\title{
FEEDBACK LINEARIZATION CONTROL FOR A DISTRIBUTED SOLAR COLLECTOR FIELD
}

\author{
Cristina M. Cirre ${ }^{(1,2)}$, Loreto Valenzuela ${ }^{(1)}$, Manuel Berenguel ${ }^{(2)}$, Eduardo F. Camacho ${ }^{(3)}$ \\ ${ }^{(1)}$ CIEMAT, Plataforma Solar de Almería, \\ Ctra. Senés s/n, 04200 Tabernas, Almería, Spain \\ ${ }^{(2)}$ Universidad de Almería, Dpto. Lenguajes y Computación, \\ Ctra. Sacramento s/n, 04120, Almería, Spain \\ ${ }^{(3)}$ Universidad de Sevilla. Dpto. de Ingeniería de Sistemas y Automática, \\ Camino de los Descubrimientos s/n, 41092, Sevilla, Spain
}

\begin{abstract}
This article presents a feedback linearization control of a distributed solar collector field, which main purpose is to heat a fluid using the energy provided by the solar irradiation. The control objective is to track an outlet temperature reference manipulating the fluid flow trying to attenuate the effect of disturbances (mainly radiation and inlet temperature). A feedback linearization technique has been developed and implemented to control this nonlinear plant by merging both feedforward and feedback control. The design of the feedback controller is performed based on a linear simplified version of the system. Experiments in the real plant are shown. Copyright $(\mathrm{C} 2005$ IFAC
\end{abstract}

Keywords: Nonlinear control, PID control, Lumped-parameter-systems, Feedback Linearization, Solar Energy

\section{INTRODUCTION}

This work presents the development, implementation and test of a feedback linearization (FL) control applied to regulate the fluid temperature at the outlet of a distributed solar collector field. This method has received much attention in the last years as an alternative to linear control for nonlinear plants. In this work, the technique has been applied to a nonlinear plant with strong and continuous disturbances, in such a way that both feedback and feedforward control can be achieved. In short, FL can be described as an approach to nonlinear control design where a nonlinear system is transformed into a linear one, so any linear control design can be implemented in order to fit the desired control goal.

During the last years, many control methods have been applied to the ACUREX distributed solar collectors field of the Plataforma Solar de Almería (Spain) (Camacho, et al., 1997). From PID control to robust control techniques as QFT (Cirre, et al., 2003), predictive and adaptative control (Camacho, et al., 1994; Juuso and Valenzuela, 2003; Pickhart, 2000; Coito, et al., 1997), fuzzy logic control (Rubio, et al., 1995), etc. A feedforward action is required in most cases in order to alleviate the effect of disturbances in the controlled signal (Berenguel, et al., 1993; Camacho, et al., 1997; Meaburn and Hughes, 1996). In fact, the required response of the system cannot be guaranteed with a simple linear control technique because of the strong nonlinearities of the plant.

The FL method was applied to the ACUREX plant using a simplified distributed parameter by means of a Lyapunov function to adapt a parameter of the model (Barao, et al., 2002). This work introduces a FL controller based on a lumped parameter model of the system aimed at allowing the automatic operation of the plant both in the start up stage and in nominal operation. The control scheme resembles a 
feedfoward controller in combination with a classical feedback controller as those presented in (Camacho, et al., 1992). The difference resides in the embedded feedback from the output, which is used both for linearization and feedforward purposes.

The paper is organized as follows: section 2 presents a brief description of the plant and the control problem. Section 3 presents a lumped model of the plant, which constitutes the base for the developed control scheme. Section 4 outlines the feedback linearization design procedure and section 5 shows the experiments performed at the solar plant. Finally, section 6 presents the conclusions.

\section{THE SOLAR PLANT}

\subsection{General description}

The parabolic-trough solar field ACUREX is a facility belonging to the Plataforma Solar de Almería (PSA) placed at the desert of Tabernas (Southern of Spain). The solar field consists of 480 modules of collectors, distributed in 10 parallel rows. Each collector is made up of a reflecting parabolic surface that concentrates the direct solar radiation in a pipe placed in the parabola focal line. The solar radiation concentrated in the pipe heats up the fluid circulating through it. The collectors are oriented from the east to the west and have one axis (elevation) solar tracking system to guarantee the continuous concentration of the solar radiation in the absorber pipe. The heat transfer fluid used is thermal oil type Santotherm 55 that can be heated up to $300^{\circ} \mathrm{C}$ maximum. The oil is stored in a thermal storage tank (back in figure 1) and it is pumped from its bottom side to be heated in the field. The hot oil is returned to the top (process oil) or to the bottom of the tank (recirculation until reaching a nominal working point) by using a three-way valve placed at the outlet of the solar field. The tank has an effective capacity of $115 \mathrm{~m}^{3}$. The oil properties permit stratified energy storage according to its density. The coldest oil is at the bottom and the hot oil at the top of the tank. The hot oil can be used in electricity generation processes or for desalination. In both cases, the oil is taken from the top of the tank, so it is convenient to avoid fluctuations at the outlet of the solar field.

\subsection{The control problem}

The control problem of a solar collector field is to keep the outlet temperature of the field near a desired level (temperature setpoint or reference). This reference is established by the operator during the operation and should match the inlet conditions imposed by the steam generator of the desalination plant (more than $160^{\circ} \mathrm{C}$ ) or by a heat exchanger to feed a turbine (around $285^{\circ} \mathrm{C}$ ). Moreover, in order to avoid stress in the material of the absorber pipes, the outlet temperature should not be over $80^{\circ} \mathrm{C}$ of the inlet temperature. The plant is exposed to disturbances: inlet temperature changes (because of the stratification inside the tank), ambient temperature variations and solar radiation changes, due to the daily cycle or passing clouds, causing fast variations in the outlet oil temperature. The controlled signal can be the maximum or the average temperature of the ten collector loops. The manipulated signal is the velocity (or flow $q$ ) of the oil propelled by the pump (see figure 2 ). The flow range of the pump is $2 \cdot 10^{-3}$ to $12 \cdot 10^{-3} \mathrm{~m}^{3} \cdot \mathrm{s}^{-1}$. The nonlinearities that characterize this plant increase the difficulty to operate it. According to the input, output and disturbance values, the characteristic gains, delays and time constants change. The most difficult stage of the plant operation (from the control point of view) is the start up. For several minutes, when the system is started, the inlet temperature is higher than the outlet one (the oil inside the pipes is cooled down during the night). This may cause a conflict in the feedforward and feedback control strategies designed for nominal operation. For this reason, most of the control structures tested at the plant pass the start up stage in manual mode (controlled by the operator) until approaching the nominal operation.

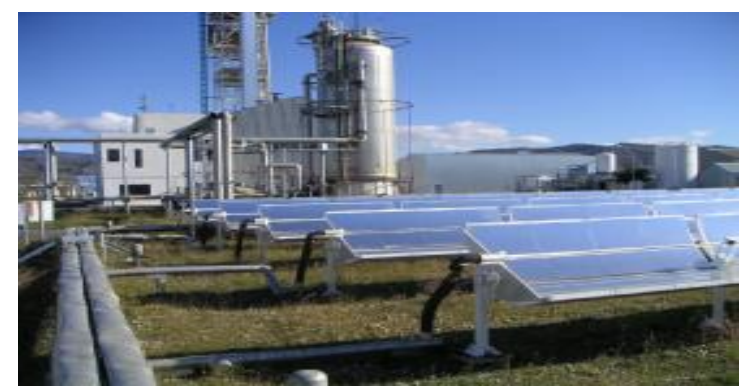

Fig. 1. Loops, pipes and tank of the ACUREX field

\section{A SIMPLIFIED PLANT MODEL}

This section outlines the characteristics of a lumped parameters physical model of the plant for control purposes, obtained from a distributed parameter nonlinear model based on partial differential equations (PDE) that can be found in (Berenguel, et al., 1994; Camacho, et al., 1997). In the following, dependences of variables with time are not explicitly written to save space, except when the variable is delayed. Equation (1) and table (1) describe the variation of the internal energy of the plant. Variables $T_{\text {in }}, T_{\text {out }}$ and $T_{\text {amb }}$ are related to the sensor measurements $\left({ }^{\circ} \mathrm{C}\right)$ of inlet temperature, outlet temperature of the controlled collector loop and ambient temperature respectively. This model has been obtained by removing the dependence with space in the original PDE model. Moreover, some experiments in the real plant to obtain parameters as the losses coefficient and the time delay of the inlet temperature have been performed. The irradiance $\left(\mathrm{W} \cdot \mathrm{m}^{-2}\right)$ is measured using a pirheliometer. This measurement is filtered and used to calculate the corrected radiation $(I)$ according to the latitude, solar hour and day of the year (see e.g. Berenguel, et al., 1994). 
The thermal losses in the solar field must be included in the lumped parameter physical model. Due to thermal losses are not theoretically known, they have been calculated based on several experiments with collectors out of tracking.

$\underline{\text { Table } 1 \text { Model descriptive variables and parameters }}$

\begin{tabular}{lcl} 
Parameter & Function/Value & Unit \\
\hline $\begin{array}{l}\text { Oil density }(\rho) \\
\text { Specific thermal }\end{array}$ & $903-0.672 \cdot T_{m}$ & $\mathrm{~kg} \cdot \mathrm{m}^{-3}$ \\
capacity $\left(C_{p}\right)$ & $1820+3.478 \cdot T_{m}$ & $\mathrm{~J} \cdot \mathrm{kg}^{-1} \cdot{ }^{\circ} C^{-1}$ \\
Mean temperature $\left(T_{m}\right)$ & $\left(T_{\text {out }}+T_{i n}\right) / 2$ & ${ }^{\circ} \mathrm{C}$ \\
Pipe cross-section area $(A)$ & 0.0006 & $\mathrm{~m}^{2}$ \\
Optical efficiency $(\alpha)$ & 0.78 & - \\
Collector loop length $(L)$ & 172 & $\mathrm{~m}$ \\
Total solar field length $\left(L_{\mathrm{t}}\right)$ & 1751 & $\mathrm{~m}$ \\
Collector aperture $(G)$ & 1.83 & $\mathrm{~m}$ \\
Fluid velocity $(v)$ & $q / A$ & $\mathrm{~m} \cdot \mathrm{s}^{-1}$ \\
Thermal losses function $\left(\tilde{H}_{l}\right)$ & eq. $(2)$ & $\mathrm{J} \cdot \mathrm{s}^{-1}$
\end{tabular}

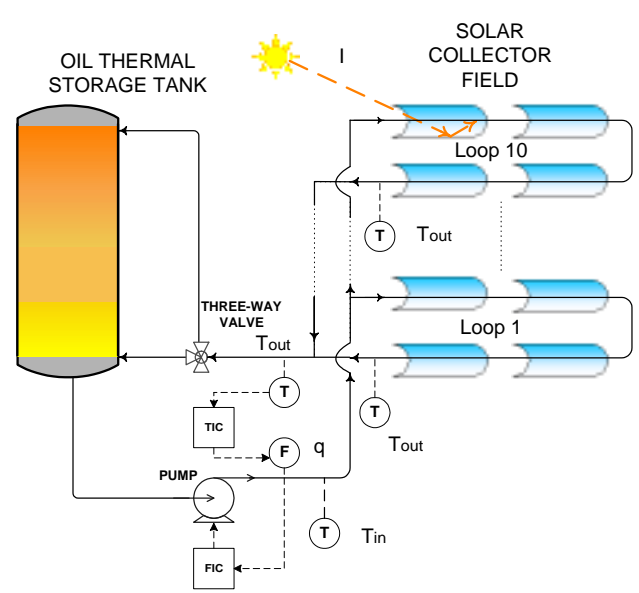

Fig. 2. Diagram of the ACUREX field

$$
\begin{aligned}
& \rho\left(T_{m}\right) \cdot C_{p}\left(T_{m}\right) \cdot A \cdot \frac{d T_{\text {out }}}{d t}=\alpha \cdot G \cdot I- \\
& -\rho\left(T_{m}\right) \cdot C_{p}\left(T_{m}\right) \cdot A \cdot v \cdot \frac{T_{\text {out }}-T_{\text {in }}\left(t-d_{\text {tin }}\right)}{L}-\frac{H_{l}^{\circ}\left(T_{m}, T_{\text {amb }}\right)}{L_{t}}
\end{aligned}
$$

Equation (2) shows $\left(\mathrm{J} \cdot \mathrm{s}^{-1}\right)$ an empirical function that provides the global thermal losses as a function of the average temperature between the inlet and the outlet, and the ambient temperature. The coefficient of determination is 0.99 .

$$
\tilde{H}_{l}=1970 \cdot\left(T_{m}-T_{a m b}\right)-34651
$$

Previous lumped parameters models (e.g. Carmona, 1985; Camacho, et al., 1997) designed for control purposes did not take into account the variable time delay between the inlet and the outlet temperatures. This delay depends on the flow and the selected loop. Equation (3) shows an expression obtained experimentally of the inlet-outlet time delay dtin (in seconds) depending on the oil flow. This equation embodies residence times calculations based on different pipe areas and approximates a piecewise expression. Coefficients $\mathrm{A} 1, \mathrm{t} 1$ and $\mathrm{y} 0$ vary depending on the collector loop whose temperature is being controlled (they are not shown to save space). The maximum delay (24 minutes) occurs in loop number ten with minimum flow and the minimum delay (maximum flow in loop number one) is around 2 minutes.

$$
d_{\text {tin }}=A_{1} \cdot e^{-\left(q / t_{1}\right)}+y_{0}
$$

The inclusion of the variable inlet time delay in the model plays an important role mainly at the starting phase of the operation, as will be shown in experimental results.

\section{FEEDBACK LINEARIZATION CONTROL}

The FL method is an approach to nonlinear control design methods where the main idea is to transform a nonlinear system into a linear one. Closed-loop dynamics in linear form are obtained; thus any linear control method can be applied. The final approach combines a linear controller with a nonlinear term obtained from the transformation. In this work, inputoutput linearization is used to control the distributed collector field using the dynamical model shown in equation (1). For a single collector loop, the flow impelled by the pump qloop (in $1 \cdot \mathrm{s}^{-1}$ ) is given by equation (4), where nope is the number of operative loops.

$$
\text { qloop }=\frac{q}{\text { nope }}
$$

The controllability canonical form (Slotine, 1991) of the system represented by equations (1) and (2) is shown in equation (5).

$$
\begin{aligned}
& \mathcal{L}_{\text {out }}^{\alpha}=\frac{\alpha \cdot G \cdot I}{\rho\left(T_{m}\right) \cdot C_{p}\left(T_{m}\right) \cdot A}- \\
& -\frac{q \cdot\left(T_{\text {out }}-T_{\text {in }}\left(t-d_{\text {tin }}\right)\right)}{A \cdot \text { nope } \cdot L}-\frac{H_{l} /\left(T_{m}, T_{\text {amb }}\right)}{\rho\left(T_{m}\right) \cdot C_{p}\left(T_{m}\right) \cdot A \cdot L_{t}}
\end{aligned}
$$

Notice that, in order to analyze the controllability of the plant, the system in equation (5) has a relative degree equal to one, the same than the order of the system (Slotine, 1991; Isidori, 1995). For systems that can be represented in the form $\hat{x}=f(x)+b(x) \cdot u$, a nonlinear mapping can be used to transform the system into a linear one:

$$
u=\frac{u^{\prime}-f(x)}{b(x)}
$$

with the condition that $\mathrm{b}(\mathrm{x})$ can not be equal to zero. The control input chosen for the system (5) is given by equation (7), where $u^{\prime}$ is the called virtual signal and $\mathrm{Hl}$ is the global thermal losses function (in Js$1 \mathrm{~m}-1)$ given by equation (8). Notice that the control input has been chosen in order to cancel the nonlinearities and that the nonlinear functions $\mathrm{f}(\mathrm{x})$ and $b(x)$ in (6) are related with the physical lumped 
parameter model in equation (1).

$$
\begin{gathered}
q=\frac{\text { nope } \cdot L \cdot \alpha \cdot G \cdot I}{\rho\left(T_{m}\right) \cdot C_{p}\left(T_{m}\right) \cdot\left(T_{\text {out }}-T_{\text {in }}\left(t-d_{\text {tin }}\right)\right)}- \\
-\frac{n o p e \cdot L \cdot H_{l}\left(T_{m}, T_{\text {amb }}\right)}{\rho\left(T_{m}\right) \cdot C_{p}\left(T_{m}\right) \cdot\left(T_{\text {out }}-T_{\text {in }}\left(t-d_{\text {tin }}\right)\right)}-\frac{u \cdot A \cdot n o p e \cdot L}{\left(T_{\text {out }}-T_{\text {in }}\left(t-d_{\text {tin }}\right)\right)} \\
H_{l}=\tilde{H}_{l} / L_{t}
\end{gathered}
$$

The resulting linear input-output relationship is the simplest one:

$$
\mathcal{T}_{\text {out }}=u^{\prime}
$$

Thus, it is possible to apply any linear control method in order to obtain the virtual signal, and then the transform given by (7) can be applied to obtain the real control signal. Notice that input-output linearization can be practically achieved in all those cases in which outlet temperatures are higher than inlet temperatures, which practically covers all the operation regimes. Only the plant start up has to be supervised to avoid numerical problems. In order to control the linearized system, a basic IPD control structure has been chosen. A first set of parameters of the IPD controller (Ogata, 1998) were obtained by using a plant simulator (Berenguel, et al., 1994) and tuning the parameters using the minimum ITAE rules (Ogunnaike, 1994), that were subsequently refined at the real plant to improve the response of the system. The IPD parameters were fixed to $K_{\text {pid }}=0.015 \mathrm{~s}^{-1}, T_{i}$ $=300 \mathrm{~s}, T_{d}=50 \mathrm{~s}$. A diagram of the final control structure is shown in figure 3 . A sampling time of 39 s was chosen.

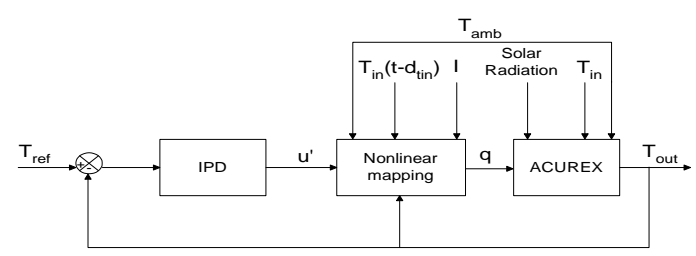

Fig. 3. Feedback linearization controller

During the start up stage, the inlet temperature may be higher than the outlet one. This fact may cause that the temperature difference in (7) be negative.

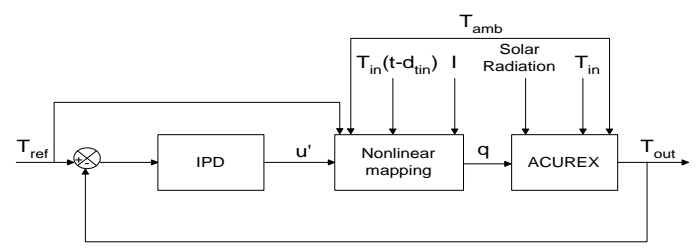

Fig. 4. Control diagram for the start up stage

For this reason, during this period the same control structure is used, but the feedback signal used in the nonlinear mapping is the reference temperature instead of the outlet temperature (figure 4). This modification provides a positive enthalpy difference as is the normal situation during operation. The benefits of using the structure showed in figure 4 during the start up will be observed in results presented in section 5. Once the outlet temperature reaches the reference the control scheme is switched to the nominal one shown in figure 3 .

As has been pointed out in the introduction, the control scheme shown in figure 3 resembles those of feedforward controllers (Camacho, et al., 1992; Camacho, et al., 1997), that were also based on a simplified physical model of the system, but considering steady state conditions, in such a way that a correlation for the oil flow as function of the inlet and outlet oil temperatures, solar radiation, mirror reflectivity and ambient temperature could be derived. Both parallel and series implementations were obtained by substituting the outlet temperature by the reference temperature (parallel implementation) or an internal reference temperature to the feedforward term (series implementation). Thus, the main difference with the scheme presented in this work is that now an internal feedback is included both for linearizing and disturbance cancellation purposes, providing smother control actions.

An anti-reset windup strategy has also been included to account for possible saturations in the control signal. The physical limits in the pump can be mapped into limits in the virtual control signal $\mathrm{u}^{\prime}$ using again the nonlinear mapping represented by equation (7). The physical limits in the real control signal are transformed into variable constraints in the virtual control signal that depend on the operating conditions. This mechanism has provided very useful results mainly during the start up stage of the operation. Notice that also a modifier of the optical efficiency can be easily included in order to modulate the disturbance rejection capabilities of the scheme.

\section{EXPERIMENTAL RESULTS}

This section presents several experiments performed in the ACUREX solar field. Both the set point tracking features and the disturbance rejection capabilities of the system have been tested under varying operating conditions due to changes in set point, irradiation and inlet oil temperature variables. The start up stage and full day operation are also shown. Figure 5 shows the system response to changes in set point signal and the inlet oil temperature. The start up stage is quite short working in automatic mode using the structure shown in figure 4 . In approximately 30 minutes the system reaches the steady state without overshoot, what is considered an excellent performance for this facility. The settling time $( \pm 5 \%)$ of the system when changes of $10^{\circ} \mathrm{C}$ in the reference temperature are performed is about 10.4 minutes. The inlet temperature varied during the test with both slow and fast dynamics. Smooth and slow changes are produced mainly during the starting up phase and are due to the mixing of hot and cold oil inside the tank (from 11.5 to $13 \mathrm{~h}$ in figure 5). As can be seen, the disturbance is 
compensated by the control system without producing appreciable errors in the tracking performance of the controlled system.

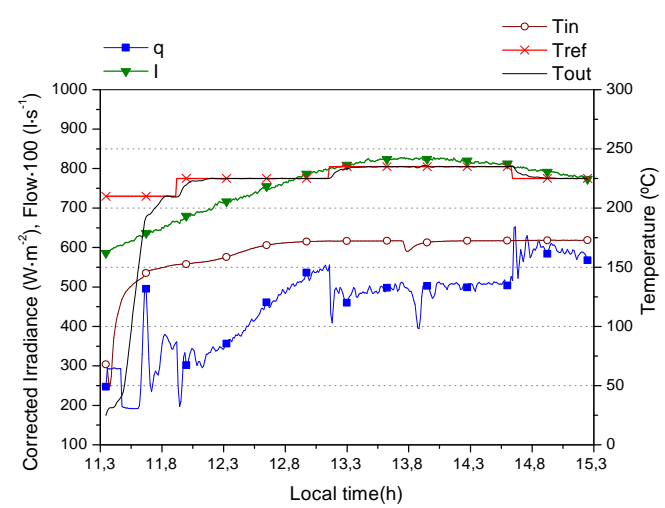

Fig. 5. Test on July $15^{\text {th }}, 2004$ with low radiation and inlet oil temperature disturbances

Around $13.75 \mathrm{~h}$, a fast disturbance is produced in the inlet oil temperature due to a commutation of the three-way valve aimed at sending the oil to the bottom of the storage tank. In this case, a change of $10^{\circ} \mathrm{C}$ in the inlet oil temperature caused a maximum tracking error of $1.2^{\circ} \mathrm{C}$ in the outlet oil temperature, which was disturbed only during three minutes.

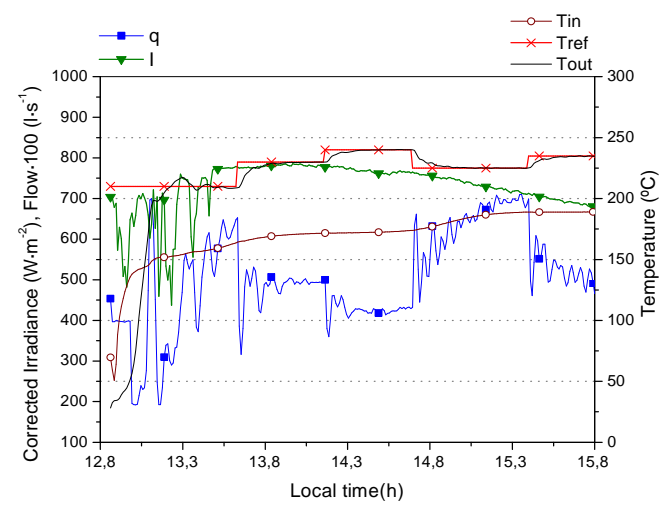

Fig. 6. Test on July $16^{\text {th }}, 2004$ with radiation and inlet oil temperature disturbances

Another test is presented in figure 6 where the influence of irradiation and inlet oil temperature disturbances are of special interest. In this case, the start up stage is very complicated for the automatic control system due to the presence of clouds that produced variations in solar radiation of about 350 $\mathrm{W} \cdot \mathrm{m}^{-2}$. This kind of disturbances added to the tracking requirements (involving fast increments in the outlet oil temperature) and the changes and long delay associated to the inlet oil temperature are a hard task for any automatic control system. Despite of this, the outlet oil temperature overshot the reference temperature around $7^{\circ} \mathrm{C}$. Moreover, a smooth variation in the inlet oil temperature of $16^{\circ} \mathrm{C}$ was rejected by the control system without appreciable tracking error. The settling time of the system after steps of $10^{\circ} \mathrm{C}$ in the reference temperature and with presence of mist is around 15 minutes without overshoot.

Figure 7 shows another experiment where the start up stage is different. The cold oil resident inside the pipes of the field is sent to the bottom of the storage tank instead of the top. This causes different changes in the inlet oil temperature. For this reason the initially established reference temperature was diminished, in order to avoid long lasting saturations in the controller output at the minimum flow, what is a natural way of operation under this circumstances (even under manual operation). As it can be seen, the system then reached the steady state without overshoot. To reject the inlet oil temperature disturbance the controller had to perform fast changes in the demanded oil flow covering the operating range of this variable. The performance of the rest of the operation is comparable to that of the previous tests, with settling times of about 10 minutes without overshoot facing changes in the set point of $10^{\circ} \mathrm{C}$. Smooth changes of the irradiation of about $70 \mathrm{~W} \cdot \mathrm{m}^{-2}$ and inlet oil temperature increases were compensated in such a way that no tracking errors were obtained.

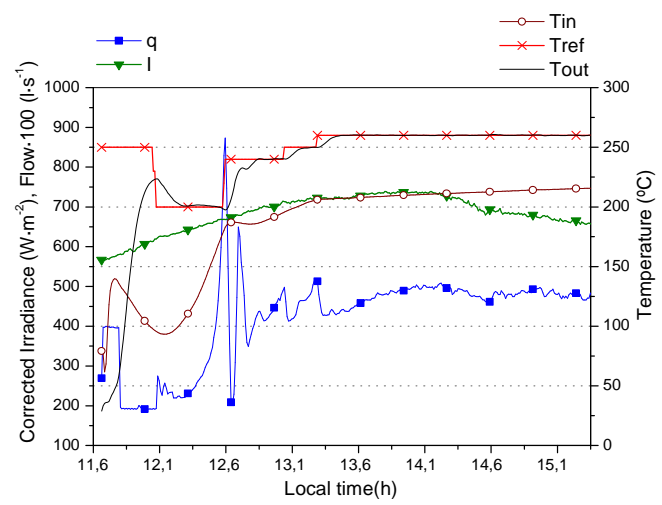

Fig. 7. Test on July $21^{\text {th }}, 2004$ with strong inlet oil temperature disturbance

It is interesting to comment that in the representative results shown in this work, the response of the system under different operating conditions (mainly represented by different values of reference temperature, oil flow, solar radiation and inlet oil temperature) is of similar nature and fits completely the operating requirements.

\section{CONCLUSIONS}

This paper presents the development of an automatic control approach using a simple FL method and a lumped parameter model of a distributed solar collector field of a solar power plant. The model used to perform the nonlinear mapping in the feedback linearization scheme has been improved when compared to existing ones to account for the varying delays between the inlet and the outlet temperatures. This part is of great relevance in order to improve the performance of the model during the start up stage and when disturbances in the inlet oil temperature 
occur, where other models fail to reflect the real dynamical behaviour. The simplified physical model has been used to design an input-output FL controller where the design of the controller is performed on a linear representation of the system as the nonlinear dynamics are embedded in the definition of a virtual control signal. Conditions for the existence of a FL controller are fulfilled whenever the outlet oil temperature is higher than the inlet temperature. This occurs always during nominal operation and is assured during the start up stage by replacing the real outlet oil temperature by the reference temperature, thus helping to improve the dynamical response of the system during this phase. Any linear controller could be used in the design of the linear part of the control system. In this work, an IPD has been chosen and implemented at the real plant. The way in which the nonlinear mapping has been performed also allows implementing an anti-reset windup strategy by simply mapping the physical constraints to limits in the virtual control variable. Although those are variables in time as they are dependent on the operating conditions, this fact does not impose any limitation in the implementation of the control scheme. Its usefulness and good behaviour have been demonstrated when starting operation.

The developed automatic control system has been implemented and tested in the real plant showing excellent results both in tracking and disturbance rejection capabilities. Special attention has been paid to the start up stage that is driven automatically by the controller in a short period of time and free of oscillations. This response is unusual in many different control approaches tested at the same plant. The experiments show that the controller is very suitable for this kind of solar plants. It combines simplicity with very good performance. The nonlinear nature of the system and the influence of disturbances are easily embedded in the nonlinear mapping representative of the FL technique. The developed feedforward-feedback controller is able to control the plant over the whole range of other operating conditions, without requiring parameter identification typical of adaptive control mechanisms (e.g. Camacho, et al., 1997; Coito, et al., 1997; Pickhardt, 2000) or controller commutation like in gain-scheduling controllers (e.g. Camacho, et al., 1997; Johansen, et al., 2000) which have shown to be a good control approximation to control this kind of system.

\section{ACKNOWLEDGEMENTS}

This work has been financed by CICYT-FEDER funds (projects DPI2001-2380-C02-02, DPI200204375-C03 and DPI2004-07444-C04-01/04) and by the Consejería de Innovación, Ciencia y Empresa de la Junta de Andalucía. This work has been also performed within the scope of the specific collaboration agreement between the Plataforma Solar de Almería and the Automatic Control, Electronics and Robotics (TEP197) research group of the Universidad de Almería titled "Development of control systems and tools for thermosolar plants".

\section{REFERENCES}

Barao, M., Lemos J.M. and Silva R.N. (2002). Reduced complexity adaptative nonlinear control of a distributed colletor solar field. Journal of process control, 12, 131-141.

Berenguel, M., Camacho, E.F:, Rubio, F.R. (1994) Simulation software package for the ACUREX field, Internal report ESI Sevilla. http://www.esi.us.es/ rubio.

Camacho, E.F., Rubio, F.R., Hughes F.M. (1992). Self-tuning control of a solar power plant with a distributed collector field. IEEE Control Systems Magazine, pp. 72-78.

Camacho, E.F., Berenguel, M., Bordóns, C .(1994) Adaptive Generalized Predictive Control of a Distributed Collector Field. IEEE Trans. On Control Systems Technology, 2, 4, 462-467.

Camacho, E.F., Berenguel, M., Rubio, F.R. (1997). Advanced Control of Solar Plants. Springer, UK.

Carmona, R. (1985). Análisis, Modelado y Control de un Campo de Colectores Solares Distribuidos con Sistema de Seguimiento de un eje. Ph.D Thesis. Universidad de Sevilla, Spain.

Cirre, C.M., Moreno, J.C., Berenguel, M. (2003) Robust QFT Controller of a Solar Collector Field. The Improving Human Potential Programme. CIEMAT, 27-35.

Coito, F., Lemos, J.M., Silva, R.N. and Mosca E. (1997). Adaptive control of a solar energy plant: exploiting acceptable disturbances. Int. Journal of Adaptive Control and Signal Processing, 11,4, 327-342.

Isidori, A. (1995). Nonlinear control systems. Springer, UK.

Johansen, T.A., Hunt, K.J. and Petersen, I. (2000). Gain-scheduled control of a solar power plant, Control Engineering Practice, 8,9, 1011-1022.

Juuso E., Valenzuela L. (2003), Adaptive Intelligent Control of a Solar Collector Field. 3rd European Symp. on Intelligent Technologies, Hybrid Systems and their implementation on Smart Adaptive Systems (EUNITE 2003), Oulu, Finland.

Meaburn, A. and Hughes, F.M. (1996). Feedforward control of solar thermal power plants. ASME Transactions, Journal of Solar Energy Engineering.

Ogata, K. (1998). Modern control engineering (in Spanish). Prentice-Hall. México.

Ogunnaike, B.A., Harmon, W. (1994). Process dynamics, modeling and control. Academic Press, USA.

Pickhardt, R. (2000). Nonlinear modelling and adaptive predictive control of a solar power plant, Control Engineering Practice, 8,8, 937-947.

Rubio, F., Berenguel, M., Camacho, E.,(1995) Fuzzy logic control of a solar power plant. IEEE Trans. on Fuzzy Systems, 3, 4, 459-468.

Slotine, J., Li, W. (1991). Applied nonlinear control, Prentice Hall, USA. 